\title{
Assessment of mulberry leaf as a potential feed supplement for animal feeding in P.R. China
}

\author{
Ming Cai ${ }^{1,2, a}$, Lan Mu ${ }^{1,2, a}$, Zong-li Wang ${ }^{1,3}$, Jian-yong Liu' ${ }^{2}$, Tian-liang Liư ${ }^{2}$, \\ Metha Wanapat ${ }^{4, *}$, and Bi-zhi Huang ${ }^{2, *}$
}

\footnotetext{
* Corresponding Authors:

Metha Wanapat

Tel: +66-0819324180, Fax: +66-043-202368

E-mail: metha@kku.ac.th

Bi-zhi Huang

Tel: +86-087167391020, Fax: +86-087167391381,

E-mail: hbz@ynbp.cn

'State Key Laboratory of Grassland Agro-ecosystems, College of Pastoral Agricultural Science and Technology, Lanzhou University, Lanzhou, Gansu 730020, China

2 Yunnan Academy of Grassland and Animal Science, Kunming, Yunnan 650212, China

${ }^{3}$ China Animal Health And Epidemiology Center, Qingdao, Shandong 266032, China

${ }^{4}$ Tropical Feed Resources Research and Development Center, Department of Animal Science, Faculty of Agriculture, Khon Kaen University, Khon Kaen 40002, Thailand
}

a These authors contributed equally to this work and co-first authors.

ORCID

Ming Cai

https://orcid.org/0000-0002-2416-374X

Lan $\mathrm{Mu}$

https://orcid.org/0000-0002-2041-8004 Zong-li Wang

https://orcid.org/0000-0001-7271-8327

Jian-yong Liu

https://orcid.org/0000-0002-0786-3795

Tian-liang Liu

https://orcid.org/0000-0003-2563-9671

Metha Wanapat

https://orcid.org/0000-0002-7633-052X

Bi-zhi Huang

https://orcid.org/0000-0003-4308-2838

Submitted Sept 6, 2018; Revised Nov 19, 2018 Accepted Dec 14, 2018
Objective: Mulberry (Morus alba L.) is a cultivated shrub grown widely in the sub-tropical and tropical areas. It has been shown that mulberry leaf contains high levels of protein while having polyphenols as phytonutrients. Therefore, it is important to conduct an experiment to assess potential toxic level from mulberry on behavior, blood hematological and coagulation parameter using Sprague-Dawley (SD) rats.

Methods: Both male and female SD rats were given an intragastric administration of respective treatments of mulberry leaf intakes (control, low and high levels). Parameters of feed intake, hematological and coagulation of blood parameters, as well as liveweight changes were taken during the $7 \mathrm{~d}$ of adaptation, $28 \mathrm{~d}$ of treatment exposure, and $14 \mathrm{~d}$ of recovery periods, respectively. All treatment data were statistically analyzed using analysis of variance of SPSS17.0 for Windows Statistical Software following the Randomized complete block design with sex as a block.

Results: Most of the parameters of the physical symptoms of the SD rats, were not significantly different $(\mathrm{p}>0.05)$ when compared with that of the control group. Those which remain unchanged in each dose group were, body weight (BW) gain, feed intake, the hematology and coagulation indexes. Although, there were a few individual indicators that were abnormal, but the overall physiological appearance of the rats were normal.

Conclusion: Results under this experiment revealed that most hematological and coagulation parameters of the SD rats in both male and female were normal, although the weight gain of female rats in high-dose group was significantly reduced than those of the male rats. Under this study, the use of mulberry leaf up to $2 \mathrm{~g} / \mathrm{kg} \mathrm{BW}$ did not result in abnormal phenomenon in the SD rats. These findings would offer useful information for further in vivo feeding trials in animals to extensively use of mulberry leaf to improve animal production, particularly in P.R. China.

Keywords: Mulberry Leaf; Sprague-Dawley Rat; Toxic Level; Protein Resource

\section{INTRODUCTION}

Mulberry (Morus alba L.) is native to northern and central China. It is cultivated in a wide range of climates because it is highly adaptable and can survive well in harsh conditions [1-3]. It is cultivated in most areas of the world, including East Asia, Southeast Asia, Europe, Africa, and America [4-6]. In fact, China has an extensive history of "mulberry sericulture cultivation". In the past, the traditional silk industry has played an extremely important role in the development of China Silk Road and in foreign trade. However, in recent times silkworm culture in China has decreased, and a large amount of mulberry leaves remains unused. A previous report estimated that the annual output of mulberry leaves was as high as 20 tons per hectare. However, only $1 \%$ to $3 \%$ of total biomass was utilized as sericulture resource, 
causing a great economic loss for silkworm and mulberry farmers. Thus, there is a critical need to transform the traditional mulberry sericulture model to a new and diversified model. Previous studies have suggested that mulberry leaves are rich in nutrients especially high in crude protein content (20\% of dry matter). In fact, it could be comparable to the high-quality legume alfalfa (Medicago sativa L.). Mulberry, in addition has good palatability and is rich in various fatty acids, minerals, vitamins, suitable bioactive substances (chlorogenic acid, benzoic acid, rutin, and astragalin) and phytonutrients (condensed tannins and saponins) [7-12]. If these mulberry resources can be processed for feeding, the pollution caused by burning could be alleviated, and it could also effectively be used as a high-quality protein forage resources, available for animal feeding in the winter and spring seasons. This could promote the healthy and sustainable development of animal husbandry in China and other countries, leading to improved economic, social, and ecological benefits. Therefore, there is a great potential for the development and utilization of mulberry leaves, as livestock and poultry feeds.

Previous studies reported that mulberry leaves were used in aquaculture, poultry, and livestock farming with beneficial outcomes [13-15]. However, in addition to a variety of nutrients, mulberry leaves also contain high level of antinutritional factors and some active substances, such as tannins, phytic acid etc. These could be potentially negative factors that could reduce the animals' digestion of nutrients. In addition, they could combine with calcium, iron, magnesium, zinc, and other metal ions to form insoluble compounds, reducing their effectiveness. Thus, if insufficient attention is given during the feeding process, there could be an adverse effect of their utilization in animal production [16-18]. It was previously reported that adding 5\% mulberry leaf powder in grass carp feed did not affect the growth performance. But when the additive amount reaches $10 \%$, the growth performance of grass carp decreased. Mulberry leaf surface is covered with waxy layer, which is difficult to digest and use in non-ruminants. Currently, there is limited information available on the feeding safety of mulberry leaves. Further research investigation regarding antinutritional factors, the modulation of feed processing, and the systematic feeding in ruminant is still required.

Therefore, the present study investigated the effects of toxicity from mulberry leaves levels on behavior, blood hematological and coagulation parameters in male and female Sprague-Dawley (SD) rats.

\section{MATERIALS AND METHODS}

Animal management and experimental procedures for this study was conducted under the regulations of Guide for Laboratory Animal Administration in Gansu Province (Gansu Provincial Department of Science and Technology, 2005). All efforts were made in this study to minimize the suffering of the rats.

\section{Experimental feeds}

Fresh leaves of mulberry were harvested from Chongqing city, China. The leaves were air dried and ground into powdery form. Samples of the powdered leaf meal were mixed in to distilled water and sodium carboxymethyl cellulose (saline water) (mulberry powder 50 g: saline water $950 \mathrm{~mL}$, T2; mulberry powder $100 \mathrm{~g}$ : saline water $900 \mathrm{~mL}, \mathrm{~T} 3$ ) and administered to the experimental rats.

\section{Experimental animals}

Sixty SD rats (SCXK-Diank2015-002-license), male (30) and female (30), about 5 to 7 weeks of age weighting about $200 \mathrm{~g}$ and $175 \mathrm{~g}$ for male and female respectively. The experiment used a randomized complete block design (RCBD) to study both male and female SD rats, which received mulberry leaves at 1 of 3 levels. Treatments were as follows; T1 = control, T2 $=1 \mathrm{~g} / \mathrm{kg}$ body weight (BW, mulberry powder $50 \mathrm{~g}$ : saline water $950 \mathrm{~mL}$ ), T3 = $2 \mathrm{~g} / \mathrm{kg}$ BW (mulberry powder $100 \mathrm{~g}$ : saline water $900 \mathrm{~mL}$ ).

\section{Feeding environment and management}

Animals were raised in a general animal laboratory environmental with a temperature of $20^{\circ} \mathrm{C}$ to $26^{\circ} \mathrm{C}$ and a humidity of $40 \%$ to $70 \%$. Animals were kept in a transparent rat cage $40.5 \times 25 \times 20 \mathrm{~cm}$ (length $\times$ width $\times$ height $)$ that had a stainless steel cage cover. The rats were fed an SPF-grade rat growth and breeding feed from the Beijing Keao Xieli Feed Co., Ltd. (Beijing, China: production license number: SCXK (Beijing) 2012-0019). Rats had ad libitum access to purified tap water during the experiment. Their cages contained sterilized corncob bedding that was replaced twice a week along with cage changing, cleaning, and disinfection.

\section{Treatments and management of the experimental rats} During testing, SD rats were acclimated for 7 days. The gavage treatment and recovery period were 28 days and 14 days, respectively.

A dose of $1 \mathrm{~g} / \mathrm{kg} \mathrm{BW}$, and $2 \mathrm{~g} / \mathrm{kg} \mathrm{BW}$ was administered to the low and high dose respectively. In addition, there was a solvent control group. There were 10 male and 10 female rats in each treatment group. Each group was administered with respective treatment via intragastric gavage once a day for 28 days, and the gastric perfusion volume was $20 \mathrm{~mL} / \mathrm{kg}$. Rats were observed once a day for general signs of distress, and the BW and feed intake were measured once a week. At the end of the treatment period, 7 males and 7 females from each group were randomly selected for haematology and blood coagulation analyzes. No additional treatments were imposed during the remaining 14 days. The rats were observed for general 
signs of distress once a day, and the BW was measured once a week. When the recovery period ended, the rats were collected for haematology and blood coagulation investigation.

Statistical method and analysis

The RCBD one-way analysis of variance was used for analysis of variance using the SPSS 17.0 for Windows statistical software. When the difference was significant, multiple comparisons were performed using Duncan's new multiple range test. The results are presented as mean \pm standard deviation and marked with significant levels $\mathrm{p}<0.05$ indicating the statistical significances.

\section{RESULTS}

\section{Chemical composition of mulberry leaf}

The chemical composition of mulberry leaf is shown in Table $1[19,20]$. It is notable that mulberry leaf contains a high level of crude protein ( 180 to $270 \mathrm{~g} / \mathrm{kg}$ ), intermediate of fiber (218 to $278 \mathrm{~g} / \mathrm{kg}$ neutral detergent fiber, 102 to $130 \mathrm{~g} / \mathrm{kg}$ acid detergent fiber). High concentration of $\mathrm{Ca}$ and $\mathrm{P}$ were also found $(5.0,2.2 \mathrm{~g} / \mathrm{kg})$. Condensed tannins were at $0.0054 \mathrm{~g} / \mathrm{kg}$.

\section{General behavior changes}

Rats in the low or high dose groups were administered either $1 \mathrm{~g} / \mathrm{kg}$ BW or $2 \mathrm{~g} / \mathrm{kg} \mathrm{BW}$, respectively, and the signs of possible adverse reactions were observed immediately after each administration. As soon as the gavage was administered, rats in all groups were found curling up to different extents. They also had reduced activity after each administration and gradually returned to normal after about 20 to 45 minutes. An observation of their fur, eyes, ears, mouth, nose, external genitalia, limbs, and tail revealed no abnormalities. The body temperature, secretions, and excretions were also normal. Up until the recovery period, there were no premature death cases found in any groups of SD rats. The general behavior of all rats was normal, and the spontaneous activity was remained

Table 1. Chemical composition of mulberry leaf

\begin{tabular}{lc}
\hline Items & $\mathbf{g} / \mathbf{k g ~ D M}$ \\
\hline DM & $180-270$ \\
Ash & $108-128$ \\
CP & $170-194$ \\
NDF & $218-278$ \\
ADF & $102-130$ \\
Lignin & $15-29$ \\
Ca & 5.0 \\
P & 2.2 \\
Condensed tannins & 0.0054 \\
r-Aminobutyric acid & 0.0021
\end{tabular}

$D M$, dry matter; $C P$, crude protein; NDF, neutral detergent fiber; ADF, acid detergent fiber.

\section{Female rats}

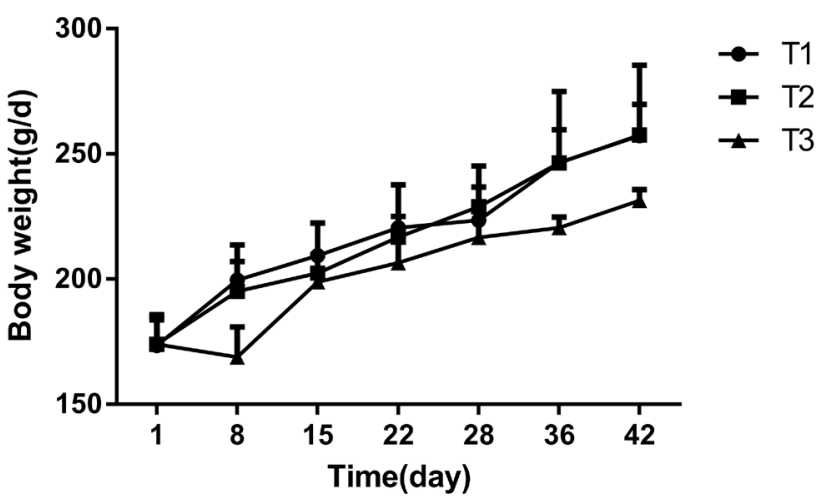

Figure 1. Effect of mulberry leaves on the body weight of Female rats. The $x$ and $y$-axes indicate time and body weight, respectively. $\mathrm{T} 1$ = control group; $\mathrm{T} 2=$ low dose group; $\mathrm{T3}$ = high dose group. Error bars are standard error of the mean.

normal. The skin coat was clean, and no toxic symptoms were observed.

Effect of mulberry leaves on the body weight of Sprague-Dawley rats

As shown in (Figures 1,2), the overall BW of each test group at the end of the gavage and the recovery period increased with time. In the early stage of the experiment, rats administered mulberry leaves had a significant reduction in BW, but the effect was gradually eliminated as the gavage time continued. Female rats in the high dose treatment-group had a significant reduction $(\mathrm{p}<0.05)$ in BW on the 8th day of treatment, when compared to both the low dose and control groups. Additionally, the BW of female rats in the high dose group was significantly decreased $(\mathrm{p}<0.05)$ on the 15th and 22 nd day of treatment, compared to the control group. On the 28th day of treatment, there was no significant difference found among the females in the high-dose, low-dose, and control groups.

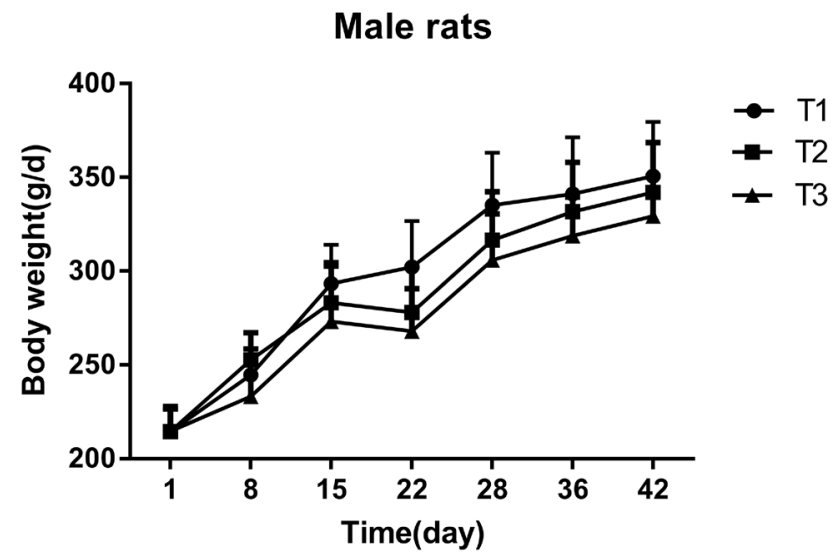

Figure 2. Effect of mulberry leaves on the body weight of male rats. The $x$ - and $\mathrm{y}$-axes indicate time and body weight, respectively. $\mathrm{T} 1$ = control group; $\mathrm{T} 2$ = low dose group; $\mathrm{T3}=$ high dose group. Error bars are standard error of the mean. 


\section{Female rats}

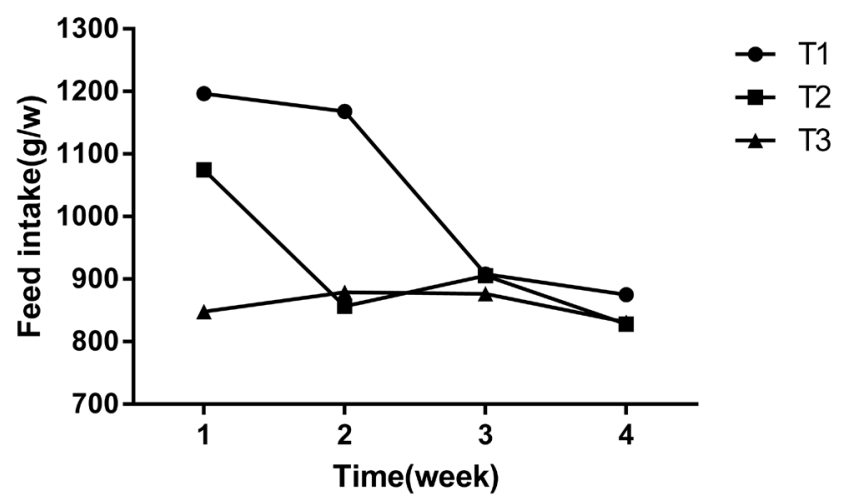

Figure 3. Effect of mulberry leaves on feed intake of Female rats. The $x$ - and $y$-axes indicate time and feed intake, respectively. $\mathrm{T} 1=$ control group, $\mathrm{T} 2=$ low dose group, $\mathrm{T} 3=$ high dose group.

The BW of male rats in the high dose group was significantly reduced on the 22nd and 28th day of treatment $(\mathrm{p}<0.05)$, when compared to the low dose and the control groups. However, there was no difference in BW between the groups during the recovery period.

\section{Effect of mulberry leaves on feed intake of Sprague-}

Dawley rats

The feed intake was measured weekly by consumption per cage of 10 rats. It was calculated as the difference between the amount of feed given and the amount of feed remaining at the end of the week. The feed intake per week of each group of rats was recorded as only one numerical value, so the feed intake data was just used as descriptive analysis. As shown in (Figures 3,4 ) the final feed intake measurement at the 4th week in the high and low dose groups was similar to the control group. The feed intake of female rats at the 1st and 2nd weeks, were lower than that of the control group, and at the 3 rd and 4th weeks it was similar to the control group. Male rats in the high dose group had slightly lower BW on the 4th week, when compared to the control group.

Effect of mulberry leaves on haematological parameters of Sprague-Dawley rats at the end of the treatment period

Statistical analysis was conducted on female and male rats separately, as well as total rats (male and female combined). High and low dose mulberry groups were compared to the control group in the same period to determine changes in hematological parameters at the end of the treatment period (Table 2). There was significant decrease $(\mathrm{p}<0.05)$ in mean corpuscular volume (MCV) levels in male rats in the high dose group. MCV and mean corpuscular hemoglobin (MCH) levels decreased in males, in the low dose group, which was significantly different from the control group $(\mathrm{p}<0.05)$. For female

\section{Male rats}

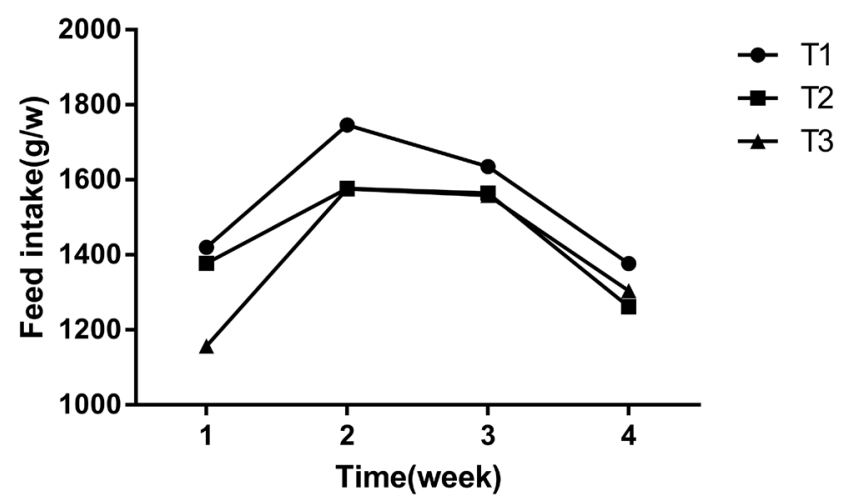

Figure 4. Effect of mulberry leaves on feed intake of Male rats. The $x$ - and $\mathrm{y}$-axes indicate time and feed intake, respectively. $\mathrm{T} 1=$ control group, $\mathrm{T} 2=$ low dose group, $\mathrm{T} 3$ = high dose group.

rats, there was no significant difference found in the various parameters. Overall, there were no differences found in various hematological parameters.

Effect of mulberry leaves on haematological parameters of Sprague-Dawley rats at the end of recovery period

Statistical analysis was conducted on all rats (male and female combined). Groups treated with the high and low doses of mulberry leaves were compared to the control group in the recovery period to determine changes in hematological parameters (Table 3 ). In the low dose group, red blood cell count and hemoglobin were significantly increased $(\mathrm{p}<0.05)$, while red cell distribution width was decreased $(\mathrm{p}<0.05)$. There were no significant differences found in other remaining parameters. $(\mathrm{p}>0.05)$.

Effect of mulberry leaves on coagulation parameters of Sprague-Dawley rats at the end of the treatment period Statistical analysis was conducted on female and male SD rats separately, as well as in total rats. The groups treated with the high and low doses of mulberry leaves were compared to the control group during the same period to determine the changes in hematological parameters at the end of the treatment period (Table 4). There was a significant increase in thrombin time (TT) found in the females of the high dose group, as well as in the total rats $(p<0.05)$. The remaining coagulation parameters were not significantly different $(p>0.05)$, which indicates that there was no toxicological symptoms.

Effect of mulberry leaves on coagulation parameters of Sprague-Dawley rats at the end of the recovery period Statistical analysis was conducted on all rats (males and females combined). Groups treated with the high and low doses of mulberry leaves were compared to the control group in the 
Table 2. Effect of mulberry leaves on hematological parameters of Sprague-Dawley rats at the end of the treatment period

\begin{tabular}{|c|c|c|c|c|c|c|c|c|c|}
\hline Items & & $T 1^{11}$ & & & $T 2^{1)}$ & & & $T 3^{1)}$ & \\
\hline Gender & Female & Male & Total & Female & Male & Total & Female & Male & Total \\
\hline WBC $\left(10^{9} / L\right)$ & $5.86 \pm 1.4$ & $8.39 \pm 2.27$ & $7.12 \pm 2.24$ & $6.40 \pm 2.02$ & $8.97 \pm 5.17$ & $7.69 \pm 4.00$ & $7.33 \pm 2.63$ & $5.50 \pm 2.40$ & $6.41 \pm 2.59$ \\
\hline Lymph (109/L) & $4.21 \pm 1.03$ & $6.01 \pm 1.73$ & $5.11 \pm 1.66$ & $4.64 \pm 1.51$ & $5.77 \pm 2.66$ & $5.21 \pm 2.16$ & $5.27 \pm 1.90$ & $3.73 \pm 1.68$ & $4.50 \pm 1.90$ \\
\hline $\operatorname{Mon}\left(10^{9} / \mathrm{L}\right)$ & $0.56 \pm 0.35$ & $0.69 \pm 0.33$ & $0.62 \pm 0.34$ & $0.53 \pm 0.22$ & $0.67 \pm 0.47$ & $0.60 \pm 0.36$ & $0.56 \pm 0.33$ & $0.40 \pm 0.34$ & $0.48 \pm 0.33$ \\
\hline $\operatorname{Gran}\left(10^{9} / \mathrm{L}\right)$ & $1.09 \pm 0.22$ & $1.69 \pm 0.57$ & $1.39 \pm 0.52$ & $1.23 \pm 0.49$ & $2.53 \pm 2.39$ & $1.88 \pm 1.79$ & $1.50 \pm 1.05$ & $1.37 \pm 0.61$ & $1.44 \pm 0.83$ \\
\hline Lymph (mg/dL) & $71.54 \pm 4.20$ & $71.47 \pm 4.80$ & 71.5 & 72.2 & 66.1 & 69.18 & 10.69 & 66.6 & 8.51 \\
\hline Mon (mg/dL) & $9.93 \pm 3.60$ & $8.61 \pm 4.18$ & 81 & $8.23 \pm 3.82$ & $8.29 \pm 4.06$ & 8.26 & $8.37 \pm 4.83$ & 7.34 & $7.86 \pm 4.35$ \\
\hline Gran $(r$ & $18.53 \pm$ & 19.91 & 19.22 & 19.5 & $25.60 \pm 7.74$ & 22.56 & 19.74 & 26.00 & 22.87 \\
\hline $\operatorname{RBC}\left(10^{12} / L\right)$ & 8.27 & & & & & & & & 1.04 \\
\hline $\mathrm{HCT}(\mathrm{mg} / \mathrm{dL})$ & $46.99 \pm 2.98$ & $51.71 \pm 3.94$ & $49.35 \pm 4.16$ & $49.40 \pm 6.18$ & $47.13 \pm 12.71$ & $48.26 \pm 9.68$ & $46.99 \pm 2.59$ & $46.90 \pm 8.58$ & $46.94 \pm 6.09$ \\
\hline $\mathrm{MCV}(\mathrm{fL})$ & $56.90 \pm 1.68^{\mathrm{a}}$ & $57.34 \pm 0.84^{\mathrm{a}}$ & $57.12 \pm 1.30^{\mathrm{a}}$ & $57.97 \pm 3.78^{\mathrm{a}}$ & $54.79 \pm 1.51^{\mathrm{bc}}$ & $56.38 \pm 3.22^{\mathrm{a}}$ & $57.11 \pm 1.80^{\mathrm{a}}$ & $55.84 \pm 0.86^{b}$ & $56.48 \pm 1.51^{\mathrm{a}}$ \\
\hline $\mathrm{MCH}(\mathrm{pg})$ & $18.11 \pm 0.52^{\mathrm{a}}$ & $18.23 \pm 0.60^{\mathrm{a}}$ & $18.17 \pm 0.54^{\mathrm{a}}$ & $18.33 \pm 0.84^{\mathrm{a}}$ & $17.44 \pm 0.45^{b}$ & $17.89 \pm 0.79^{\mathrm{a}}$ & $17.90 \pm 0.63^{\mathrm{a}}$ & $17.69 \pm 0.45^{\mathrm{a}}$ & $17.79 \pm 0.54^{\mathrm{a}}$ \\
\hline $\mathrm{MCHC}(\mathrm{g} / \mathrm{L})$ & $319.29 \pm 8.28$ & $318.57 \pm 8.70$ & $318.93 \pm 8.17$ & $317.43 \pm 8.14$ & $319.00 \pm 5.69$ & $318.21 \pm 6.80$ & $314.29 \pm 7.61$ & $317.29 \pm 6.80$ & $315.79 \pm 7.11$ \\
\hline RDW (mg/dL) & $12.70 \pm 1.44$ & $13.06 \pm 1.52$ & $12.88 \pm 1.43$ & $12.31 \pm 1.82$ & $11.79 \pm 0.52$ & $12.05 \pm 1.32$ & $13.19 \pm 1.25$ & $13.43 \pm 1.20$ & $13.31 \pm 1.18$ \\
\hline MPV (fL) & $6.07 \pm 0.44$ & $6.13 \pm 0.31$ & $6.10 \pm 0.37$ & $5.90 \pm 0.57$ & $6.01 \pm 0.18$ & $5.96 \pm 0.41$ & $6.11 \pm 0.35$ & $6.16 \pm 0.48$ & $6.14 \pm 0.40$ \\
\hline $\mathrm{DW}(\mathrm{mg} / \mathrm{dL})$ & $16.10 \pm 0.45$ & $16.01 \pm 0.28$ & $16.06 \pm 0.36$ & $16.06 \pm 0.05$ & $16.17 \pm 0.65$ & $16.11 \pm 0.45$ & $15.90 \pm 0.08$ & $16.10 \pm 0.71$ & $16.00 \pm 0.50$ \\
\hline$H G B(g / L)$ & $150.29 \pm 11.27$ & $164.86 \pm 11.47$ & $157.57 \pm 13.28$ & $156.71 \pm 17.05$ & $150.86 \pm 41.09$ & $153.79 \pm 30.38$ & $147.71 \pm 6.99$ & $149.14 \pm 27.41$ & $148.43 \pm 19.23$ \\
\hline
\end{tabular}

WBC, White blood cell count; Lymph, lymphocytes; Mon, monocytes; Gran, granulocyte; RBC, red blood cell count; HCT, hematocrit; MCV, mean corpuscular volume; MCH, mean corpuscular hemoglobin; MCHC, mean corpuscular-hemoglobin concentration; RDW, red cell distribution width; MPV, mean platelet volume; PDW, platelet distribution width; HGB, hemoglobin.

1) $\mathrm{T} 1$ = control group; $\mathrm{T} 2$, low dose group; $\mathrm{T} 3$, high dose group.

The results are presented as mean \pm standard deviation and marked with significant levels.

${ }^{a-c}$ With different superscripts in the same row indicate significant differences $(p<0.05)$.

recovery period to determine changes in coagulation parameters of rats at the end of the recovery period (Table 5). There

Table 3. Effect of mulberry leaves on hematological parameters of SpragueDawley rats at the end of recovery period

\begin{tabular}{|c|c|c|c|}
\hline Items & $T 1^{1)}$ & $T 2^{1)}$ & $T 3^{1)}$ \\
\hline WBC $\left(10^{9} / L\right)$ & $7.78 \pm 2.33$ & $7.48 \pm 6.33$ & $8.42 \pm 2.74$ \\
\hline Lymph $\left(10^{9} / \mathrm{L}\right)$ & $4.87 \pm 1.51$ & $4.42 \pm 2.83$ & $5.73 \pm 1.64$ \\
\hline $\operatorname{Mon}\left(10^{9} / \mathrm{L}\right)$ & $0.80 \pm 0.44$ & $0.58 \pm 0.48$ & $0.62 \pm 0.25$ \\
\hline $\operatorname{Gran}\left(10^{9} / \mathrm{L}\right)$ & $2.12 \pm 0.86$ & $2.48 \pm 3.13$ & $2.07 \pm 1.14$ \\
\hline Lymph (mg/dL) & $62.52 \pm 6.77$ & $64.22 \pm 8.43$ & $68.65 \pm 4.40$ \\
\hline Mon (mg/dL) & $10.78 \pm 4.62$ & $8.40 \pm 2.60$ & $7.27 \pm 2.28$ \\
\hline $\operatorname{Gran}(\mathrm{mg} / \mathrm{dL})$ & $26.70 \pm 7.67$ & $27.38 \pm 9.16$ & $24.08 \pm 6.30$ \\
\hline $\mathrm{RBC}\left(10^{12} / \mathrm{L}\right)$ & $8.06 \pm 0.57^{\mathrm{a}}$ & $8.72 \pm 0.44^{b}$ & $8.49 \pm 0.55^{\mathrm{a}}$ \\
\hline $\mathrm{HCT}(\mathrm{mg} / \mathrm{dL})$ & $44.85 \pm 3.31$ & $48.60 \pm 3.25$ & $46.72 \pm 3.67$ \\
\hline MCV (fL) & $55.72 \pm 1.83$ & $55.87 \pm 2.48$ & $55.07 \pm 2.23$ \\
\hline $\mathrm{MCH}(\mathrm{pg})$ & $17.80 \pm 0.76$ & $18.10 \pm 1.00$ & $17.87 \pm 0.64$ \\
\hline MCHC (g/L) & $320.00 \pm 6.99$ & $324.83 \pm 6.79$ & $325.00 \pm 2.10$ \\
\hline $\mathrm{RDW}(\mathrm{mg} / \mathrm{dL})$ & $14.27 \pm 1.22^{\mathrm{a}}$ & $12.75 \pm 1.00^{b}$ & $14.00 \pm 1.11^{\mathrm{a}}$ \\
\hline MPV (fL) & $5.78 \pm 0.26$ & $5.93 \pm 0.28$ & $5.98 \pm 0.39$ \\
\hline PDW (mg/dL) & $15.83 \pm 0.08$ & $15.85 \pm 0.14$ & $15.88 \pm 0.10$ \\
\hline$H G B(g / L)$ & $143.67 \pm 9.63^{\mathrm{a}}$ & $158.17 \pm 12.61^{b}$ & $152.00 \pm 11.05^{a}$ \\
\hline
\end{tabular}

WBC, White blood cell count; Lymph, lymphocytes; Mon, monocytes; Gran, granulocyte; RBC, red blood cell count; $\mathrm{HCT}$, hematocrit; $\mathrm{MCV}$, mean corpuscular volume; $\mathrm{MCH}$, mean corpuscular hemoglobin; $\mathrm{MCHC}$, mean corpuscular-hemoglobin concentration; RDW, red cell distribution width; MPV, mean platelet volume; PDW, platelet distribution width; HGB, hemoglobin.

1) $\mathrm{T} 1$, control group; $\mathrm{T} 2$ = low dose group; $\mathrm{T} 3$, high dose group.

The results are presented as mean \pm standard deviation and marked with significant levels.

a,b With different superscripts in the same row indicate significant differences $(p<0.05)$. were no significant differences in the coagulation parameters found in the treated groups as compared to the solvent control group ( $p>0.05$ ), which indicates that there was no adverse effect.

\section{DISCUSSION}

Mulberry leaf contains high crude protein and condensed tannins. The presence of condensed tannins could be useful in enhancing rumen fermentation [21]. Under this study, the condensed tannins were relatively higher than those found in other reports [21].

With the advancement of human society and the rapid development of agriculture and animal husbandry, the demand for meat, milk, eggs, and poultry food products for human consumption have been rising, and thus, food safety and security awareness is increasing. There is often a shortage of high-quality protein feed and an insufficient supply of green forage during the winter and spring feeding season. This greatly limits the output of livestock and poultry food products, and it threatens the safety and security of livestock and poultry food production. Livestock and poultry are highquality protein foods for humans. Therefore, the quality of livestock and poultry feed ingredients is closely related to human health. Mulberry leaves are rich in nutrients especially with a high crude protein content, and they provide balanced amino acids with high digestibility [22,23]. In addition to being rich in nutrients, mulberry leaves also contain bioactive substances, such as jasmonic acid, anthocyanins, 
Table 4. Effect of mulberry leaves on coagulation parameters of Sprague-Dawley rats at the end of the treatment period

\begin{tabular}{|c|c|c|c|c|c|c|c|c|c|}
\hline Items & & $\mathrm{T} 1^{1)}$ & & & $T 2^{1)}$ & & & $T 3^{1)}$ & \\
\hline Gender & Female & Male & Total & Female & Male & Total & Female & Male & Total \\
\hline PT(s) & $14.95 \pm 2.55$ & $16.19 \pm 3.82$ & $15.57 \pm 3.18$ & $14.08 \pm 2.60$ & $16.63 \pm 2.51$ & $15.35 \pm 2.79$ & $16.71 \pm 4.59$ & $16.76 \pm 3.11$ & $16.74 \pm 3.77$ \\
\hline APTT(s) & $46.29 \pm 9.47$ & $52.50 \pm 13.96$ & $49.40 \pm 11.90$ & $56.03 \pm 14.75$ & $57.95 \pm 21.41$ & $56.99 \pm 17.69$ & $52.15 \pm 7.20$ & $48.46 \pm 6.34$ & $50.31 \pm 6.79$ \\
\hline $\mathrm{TT}(\mathrm{s})$ & $16.12 \pm 7.24^{\mathrm{a}}$ & $16.77 \pm 6.49^{a}$ & $16.45 \pm 6.61^{a}$ & $18.74 \pm 5.37^{\mathrm{a}}$ & $23.67 \pm 5.05^{\mathrm{a}}$ & $21.21 \pm 5.63^{\mathrm{a}}$ & $24.22 \pm 6.97^{b c}$ & $21.92 \pm 8.68^{a}$ & $23.07 \pm 7.66^{b}$ \\
\hline $\mathrm{FIB}(\mathrm{s})$ & $9.78 \pm 1.10$ & $8.92 \pm 1.61$ & $9.35 \pm 1.40$ & $8.86 \pm 1.67$ & $8.33 \pm 1.14$ & $8.59 \pm 1.40$ & $9.82 \pm 1.68$ & $9.51 \pm 2.83$ & $9.67 \pm 2.24$ \\
\hline
\end{tabular}

PT, prothrombin time; APTT, activated partial thromboplastin time; TT, thrombin time; FIB, fibrinogen.

${ }^{1)} \mathrm{T} 1$ = control group; $\mathrm{T2}$, low dose group; $\mathrm{T3}$, high dose group.

The results are presented as mean \pm standard deviation and marked with significant levels.

${ }^{a-c}$ With different superscripts in the same row indicate significant differences $(p<0.05)$.

flavonoids, stilbene, and terpenoids [24,25]. These bioactive substances have positive effects, such as antibacterial, antipyretic, anticancer, antioxidation, hypoglycemic, serum lipid-lowering, and metabolism-improving properties [26,27]. However, they could also influence the physiology of animals. Currently, there is limited research on the safety of the mulberry leaf if used as an animal feed. As there are large mulberry plantations in China, the quantity and quality of mulberry leaves could make it an advantageous feed resource. However, the safety and toxicological evaluation of mulberry needs to be examined before it can be promoted as a feed for livestock production.

In the current study, SD rats were orally administered mulberry leaves for 28 days, and a subacute toxicity test was conducted after 14 days of a recovery period. Throughout the experiment, the physical condition, BW, and feed intake were recorded. Blood was sampled at the end of the gavage and recovery periods for analyses of hematology and coagulation parameters to evaluate the safety use of mulberry leaves. The experiment complied with the Chinese Food Standard for the 28-day Oral Toxicity Test of National Food Safety Standard (GB 15193.22-2014). The results indicated that mulberry leaves can be considered safe. There were no adverse effects on general behavior, BW, hematology, and coagulation parameters obtained in the SD rats tested.

These parameters are important indicators of the relationship between the dosage given and symptoms of toxicity [28]. The general behavior of the rats treated with the low or high

Table 5. Effect of mulberry leaves on coagulation parameters of SpragueDawley rats at the end of the recovery period

\begin{tabular}{lccr}
\hline Items & \multicolumn{1}{c}{$\mathbf{T 1}^{{ }^{1)}}$} & \multicolumn{1}{c}{$\mathbf{T 2}^{{ }^{1)}}$} & T3 $^{{ }^{1)}}$ \\
\hline PT & $14.82 \pm 1.06$ & $14.79 \pm 2.75$ & $13.38 \pm 3.13$ \\
APTT & $33.73 \pm 10.55$ & $37.78 \pm 13.16$ & $45.59 \pm 7.43$ \\
TT & $19.25 \pm 5.12$ & $18.80 \pm 9.86$ & $16.59 \pm 6.25$ \\
FIB & $7.98 \pm 2.10$ & $8.89 \pm 1.83$ & $8.69 \pm 3.29$ \\
\hline
\end{tabular}

PT, prothrombin time; APTT, activated partial thromboplastin time; TT, thrombin time, FIB, fibrinogen.

1) $T 1$, control group; $T 2$, low dose group; $T 3$, high dose group.

The results are presented as mean \pm standard deviation and marked with significant levels. doses of mulberry leaves solution and those treated with the solvent control groups were normal. All SD rats performed well on the spontaneous activity test, and their skin coat was kept clean during the gavage and recovery periods. Furthermore, there were no cases of death, and no toxic symptoms appeared. After the treatment was administered, some rats were found curling up. This symptom could be related to the concentration of the mulberry leaves treatment solution. The maximum dose of mulberry leaves was a thick suspension with a large concentration, and the oral administration volume was $20 \mathrm{~mL} / \mathrm{kg} \mathrm{BW}$, which is a large intragastric volume for rats. After intragastric administration, the limit of gastric capacity was rapidly reached, and thus, this symptom was not due to mulberry leaf toxicity. There were no abnormal cases found in any of the experimental groups. This finding was consistent with the behavioral performance of other animals at the beginning of the treatment.

The BW and feed intake are the most sensitive indicators of toxic effects caused by a test substance. Compared with the control group, the BW of SD rats in the mulberry leaf-treated groups was significantly decreased during the initial gavage administration. This could be related to the discomfort of the initial gavage, and as the gavage period continued, the reduction in BW was gradually eliminated. A decrease in feed intake was observed, which could be due to the fact that a large volume of the test substance occupied the stomach capacity. This could reduce the feed intake, rather than a toxicological effect of the test substance itself. In general, the feed intake in the low and high dose groups at 4 weeks was lower than in the control group. A previous study indicated that the alkaloids in mulberry leaves could bind to a-glycosidase. Which could reduce the decomposition of disaccharides. In addition, the flavonoids in mulberry leaves have antioxidant activity, which promotes cells to restore insulin levels. Insulin secretion is increased, and the oxidative degradation of sugars is accelerated. This causes an impact on BW and feed intake. Mulberry leaves are capable of creating the optimum condition for rumen fermentation [29]. In the late stage of the treatment and during the recovery period, the levels of the indicators returned to normal. 
Blood plays an important role in maintaining normal metabolism in animals and maintaining a balance with the external environment. Any stimulus could affect an organism by causing changes in blood components, so blood tests are one of the most common and important tests in the diagnosis of animal diseases. Compared with the control group, the haematology and coagulation parameters of male SD rats in both the low and high dose groups were increased. The low doses group had reduced levels of MCV and MCH. However, these were slight changes, indicating that it was due to normal variability and not toxic symptoms.

For the coagulation index, prothrombin time, activated partial thromboplastin time, fibrinogen, and TT were measured to determine if the rats had haemorrhagic symptoms. Female $\mathrm{SD}$ rats in the high dose group and in the total group demonstrated an increase in TT $(\mathrm{p}<0.05)$. The detection of TT indicates that the clotting time is prolonged. This should result in an increase in heparin and hepatic substances, but the other coagulation parameters were not significantly changed ( $p>$ 0.05 ). Thus, we conclude that these changes had no clear toxicological significance because many indicators of haematology were mutually influenced, rather than independently. Since a single indicator was lacking on biological significance, it suggests that the change had no clear toxicological significance.

\section{CONCLUSION}

Under this experiment, it could be concluded that feeding the experimental rats at $2.00 \mathrm{~g} / \mathrm{kg} \mathrm{BW}$, did not reveal significant adverse effects. This experiment preliminarily verifies the safety of mulberry leaves for use as animal feed, which provides a foundation for further research and exploitation of mulberry leaves as a livestock feed. Nevertheless, in vivo feeding trials need to be conducted to evaluate more practical implications for the extensive use of mulberry leaves in animal production, particularly in P.R. China.

\section{CONFLICT OF INTEREST}

We certify that there is no conflict of interest with any financial organization regarding the material discussed in the manuscript.

\section{ACKNOWLEDGMENTS}

Authors are grateful to financial support from Special Fund for Agro-scientific Research in the Public Interest of China (Project No.201403049); China Agriculture Research System (Project No.CARS-37); Yun ling Scholar and Yunling SuperTalent Initiative-Yunling High-end Foreign Experts Program; High-tech Talents Introduction Program of Yunnan Province (Project No.2012HA012). Special thanks also extended to
TROFREC, Department of Animal Science, Faculty of Agriculture, Khon Kaen University, Thailand.

\section{REFERENCES}

1. Li RX, Li RF, Chen DD, et al. Mildew resistance Locus O gene cloning, characterization, and expression pattern in mulberry (Morus multicaulis) and its prokaryotic expression in E. coli. Russ J Bioorgan Chem 2018;44:104-11. https://doi.org/10.1134/ S1068162018010119

2. Liu XQ, Zhu JJ, Wei CJ, et al. Genome-wide identification and characterization of the DREB transcription factor gene family in inmulberry. Biol Plant 2015;59:253-65. https://doi.org/10. 1007/s10535-015-0498-x

3. Singhal BK, Khan MA, Dhar A, Baqual FM, Bindroo BB. Approaches to industrial exploitation of mulberry (Mulberry sp.) fruits. J Fruit Ornam Plant Res 2010;18:83-99.

4. Boubaya A, Marzougui N, Ferchichi A, Salah MB. Morphological and chemical diversity among South Tunisian mulberry tree (Morus spp.) cultivars. Acta Bot Gallica 2011;158:375-85. https://doi.org/10.1080/12538078.2011.10516280

5. Ercisli S, Orhan E. Chemical composition of white (Morus alba), red (Morus rubra) and black (Morus nigra) mulberry fruits. Food Chem 2007;103:1380-4. https://doi.org/10.1016/ j.foodchem.2006.10.054

6. Zerga NJC, Clement WL, Datwyler SL, Weiblen GD. Biogeography and divergence times in the mulberry family (Moraceae). Mol Phylogenet Evol 2005;37:402-16. https://doi.org/10.1016/ j.ympev.2005.07.004

7. Guan YT, Li Y. Fabrication of cotton nano-powder and its textile application. Chin Sci Bull 2008;53:3735-40. https://doi. org/10.1007/s11434-008-0518-8

8. Eadie L, Ghosh TK. Biomimicry in textiles: past, present and potential. An overview. J R Soc Interface 2011;8:761-75. https:// doi.org/10.1098/rsif.2010.0487

9. Ji T, Li J, Su SL, et al. Identification and determination of the polyhydroxylated alkaloids compounds with a-glucosidase inhibitor activity in mulberry leaves of different origins. Molecules 2016;21:206. https://doi.org/10.3390/molecules21020206

10. Kojima Y, Kimura T, Nakagawa K, et al. Effects of mulberry leaf extract rich in 1-deoxynojirimycin on blood lipid profiles in humans. J Clin Biochem Nutr 2010;47:155-61. https://doi. org/10.3164/jcbn.10-53

11.Zou YX, Liao ST, Shen WZ, et al. Phenolics and antioxidant activity of mulberry leaves depend on cultivar and harvest month in Southern China. Int J Mol Sci 2012;13:16544-53. https://doi.org/10.3390/ijms131216544

12. Katsube T, Imawaka N, Kawano Y, Yamazaki Y, Shiwaku K, Yamane $\mathrm{Y}$. Antioxidant flavonol glycosides in mulberry (Morus alba $\mathrm{L}$.) leaves isolated based on LDL antioxidant activity. Food Chem 2006;97:25-31. https://doi.org/10.1016/j.foodchem. 2005.03.019 
13.Liu JX, Yao J, Yan B, Yu JQ, Shi ZQ. Effects of mulberry leaves to replace rapeseed meal on performance of sheep feeding on ammoniated rice straw diet. Small Rumin Res 2001;39:1316. https://doi.org/10.1016/S0921-4488(00)00180-2

14. Wang C, Yang FY, Wang QG, et al. Nutritive value of mulberry leaf meal and its effect on the performance of 35-70-day-old geese. J Poult Sci 2017;54:41-6. https://doi.org/10.2141/jpsa. 0160070

15. Kandylis K, Hadjigeorgiou I, Harizanis P. The nutritive value of mulberry leaves (Morus alba) as a feed supplement for sheep. Trop Anim Health Prod 2009;41:17-24. https://doi.org/10.1007/ s11250-008-9149-y

16. Han CK, Kim SS, Choi SY, Park JH, Lee BH. Effects of rice added with mulberry leaves and fruit on blood glucose, body fat and serum lipid levels in rats. J Korean Soc Food Sci Nutr 2009;38:1336-41. https://doi.org/10.3746/jkfn.2009.38.10.1336

17.Lim HH, Yang SJ, Kim Y, Lee M, Lim Y. Combined treatment of mulberry leaf and fruit extract ameliorates obesity-related inflammation and oxidative stress in high fat diet-induced obese mice. J Med Food 2013;16:673-80. https://doi.org/10. 1089/jmf.2012.2582

18. Oku T, Yamada M, Nakamura M, Sadamori N, Nakamura S. Inhibitory effects of extractives from leaves of Morus alba on human and rat small intestinal disaccharidase activity. Br J Nutr 2006;95:933-8. https://doi.org/10.1079/BJN20061746

19.Leterme P, Londono AM, Estrada F, Souffrant WB, Buldgen A. Chemical composition, nutritive value and voluntary intake of tropical tree foliage and cocoyam in pigs. J Sci Food Agric 2005;85:1725-32. https://doi.org/10.1002/jsfa.2177

20. Hong X, Ding XW, Huang XZ, et al. Determination of the content of three bioactive substances in mulberry leaves of different varieties. Sci Seric 2013;39:1145-9. (In Chinese)

21. Wanapat M, Kang S, Polyorach S. Development of feeding systems and strategies of supplementation to enhance rumen fermentation and ruminant production in the tropics. J Anim Sci Biotechnol 2013;4:32. https://doi.org/10.1186/2049-18914-32
22.Saddul D, Jelan ZA, Liang JB, Halim RA. Evaluation of mulberry (Morus alba) as potential feed supplement for ruminants: The effect of plant maturity on in situ disappearance and in vitro intestinal digestibility of plant fractions. Asian-Australas J Anim Sci 2005;18:1569-74. https://doi.org/10.5713/ajas.2005.1569

23. Yulistiani D, Jelan ZA, Liang JB, Yaakub H, Abdullah N. Effects of supplementation of mulberry (Morus alba) foliage and urea-rice bran as fermentable energy and protein sources in sheep fed urea-treated rice straw based diet. Asian-Australas J Anim Sci 2015;28:494-501. https://doi.org/10.5713/ajas.14. 0406

24. Sohn HY, Son KH, Kwon CS, Kwon GS, Kang SS. Antimicrobial and cytotoxic activity of 18 prenylated flavonoids isolated from medicinal plants: Morus alba L., Morus mongolica Schneider, Broussnetia papyrifera (L.) Vent, Sophora flavescens Ait and Echinosophora koreensis Nakai. Phytomedicine 2004; 11:666-72. https://doi.org/10.1016/j.phymed.2003.09.005

25. Asano N, Yamashita T, Yasuda K, et al. Polyhydroxylated alkaloids isolated from mulberry trees (Morus alba L.) and silkworms (Bombyx mori L.). J Agric Food Chem 2011;49:420813. https://doi.org/10.1021/jf010567e

26. Feng RZ, Wang Q, Tong WZ, et al. Extraction and antioxidant activity of flavonoids of Morus nigra. Int J Clin Exp Med 2015; 8:22328-36.

27.Zheng SQ, Liao ST, Zou YX, Qu Z, Shen WZ, Shi Y. Mulberry leaf polyphenols delay aging and regulate fat metabolism via the germline signaling pathway in Caenorhabditis elegans. AGE 2014;36:9719. https://doi.org/10.1007/s11357-014-9719-z

28. Nwosu LC, Adedire CQ, Ogunwolu EO, Ashamo MO. Toxicological and histopathological effects of Dennettia tripetala seed used as grain protectant, food, and medicine. Food Qual Saf 2017;1:211-20. https://doi.org/10.1093/fqsafe/fyx019

29. Huyen NT, Wanapat M, Navanukraw C. Effect of mulberry leaf pellet (MUP) supplementation on rumen fermentation and nutrient digestibility in beef cattle fed on rice straw-based diets. Anim Feed Sci Technol 2012;175:8-15. https://doi.org/ 10.1016/j.anifeedsci.2012.03.020 